\title{
Forest Structure and a Sustainable Management Solution at the Permanent Plot in Bidoup-Nui Ba National Park
}

\author{
Do Thi Hong Hoa ${ }^{1,2}$, Vien Ngoc Nam ${ }^{3}$ and Luu Hong Truong ${ }^{4}$ \\ 1. Ho Chi Minh City University of Natural Resources and Environment, Ho Chi Minh City 700000, Vietnam \\ 2. Graduate University of Science and Technology, Vietnam Academy of Science and Technology, Ha Noi 100000, Vietnam \\ 3. Nong Lam University, Ho Chi Minh City 700000, Vietnam \\ 4. Southern Institute of Ecology, Vietnam Academy of Science and Technology, Ha Noi 100000, Vietnam
}

\begin{abstract}
Vietnam is one of the countries with high biological diversity in the world but also greatly influenced by climate change. Therefore, it is necessary to have a solution for sustainable forest management through field surveys in permanent plots to study forest ecology, combining advanced GIS (Geographic Information System) technologies such as Google Earth, Global Mapper, etc. to monitor changes in forest structure and dynamics. The paper is based on the inheritance of the first measurement data in 2012 and directly measures in the second time after 5 years in 2017 at a 10-ha plot with ten 1-ha subplots. The results show that the number of trees is the highest at the diameter class of $10-20 \mathrm{~cm}(<20 \mathrm{~cm})$, accounting for about $60 \%$ of the total number of trees of each 1 -ha sub-plot and the study site and at the height of $<20 \mathrm{~m}$, respectively 8,402 out of 10,261 in 2012 and 8,189 out of 10,013 in 2017 were measured. In addition, the result of this paper indicates that Google Earth software is one of the most effective GIS tools in planning biodiversity conservation strategies and natural resource management.
\end{abstract}

Key words: Forest structure, GIS, permanent plot, Bidoup-Nui Ba.

\section{Introduction}

In Vietnam, the total forest area is $14,773,000$ ha, the proportion of forest coverage of $47.6 \%$ [1]. Vietnam is one of the countries with high biological diversity in the world but also greatly influenced by climate change. In fact, the natural forest area in general and the quality of forest ecosystems along with the biodiversity in our country have been severely reduced in recent years [2]. Reducing greenhouse gas emissions from deforestation and forest degradation (REDD) in developing countries is a global initiative that has been the 13th Conference of the Parties (COP13) of the United Nations Framework Convention on Climate Change

Corresponding author: Do Thi Hong Hoa, Ph.D. student, main research fields: ecology, biotechnology, natural resources and environment management.
(UNFCCC) and Kyoto Protocol adopted in Bali, Indonesia in 2007 [3].

Therefore, sustainable forest management requires monitoring and evaluating structure and dynamics of the forest ecosystem, finding out the causes of dynamics to predict the development in the future and to plan strategies to protect, develop and sustain use of forest resources. In the last decade of the 20th century, the FAO (Food and Agriculture Organization) of the United Nations implemented a project to assess the global forest resources in order to gather information about the area and quality of forests as well as ecological indicators, thereby, define changes in forest resources periodically every 5 years to 10 years in each country. Countries have been using advanced technologies such as remote sensing and GIS (Geographic Information System) to monitor forest areas. However, the monitoring of forest quality and 
forest ecological factors requires a lot of efforts through field surveys in permanent plots to study forest ecology [4].

A GIS is a system designed to capture, store, manipulate, analyze, manage and present spatial or geographic data. GIS applications are tools that allow users to create interactive queries (user-created searches), analyze spatial information, edit data in maps, and present the results of all these operations [5]. With the development of GIS, environmental and natural resources managers have information systems at their disposal, data of which are readily accessible, easily combined and flexibly modified for decision making in environmental and natural resources management [6]. Google's freely available Google Earth software provides many functions that can be used as GIS tools to support natural resources management activities. Google Earth, which lets you view and work with satellite imagery, maps, aerial photos, and other imagery, is available in three versions: the free version, Google Earth Pro., and Google Earth Enterprise [7].

This study uses the Google Earth Pro. tool to manage forest resources at the permanent plot in Bidoup, Nui Ba National Park scientifically, easily updated, accurately and effectively.

\section{Methodology}

The study area in the permanent plot at Bidoup-Nui Ba National Park was established by the SIE (Southern Institute of Ecology) since 2012 under the State's key science-technology program "Science and Technology for Serving Tay Nguyen Region's Social-Economic Development" KHCN-TN3/11-15 Project (Tay Nguyen 3) "Establishing a forest dynamics plot in Bidoup-Nui Ba National Park as foundation for studies in forest succession". Bidoup-Nui Ba National Park with a total area of 65,188 hectares in the Northeast of Da Lat Highland, has coordinates $12^{\circ} 00^{\prime}$ $\mathrm{N}$ to $12^{\circ} 19^{\prime} \mathrm{N}$ and $108^{\circ} 21^{\prime} \mathrm{E}$ to $108^{\circ} 44^{\prime} \mathrm{E}$. The 25 -ha plot is designed with 25 small plots of 1 ha, size $20 \mathrm{~m}$ $\times 500 \mathrm{~m}$. Each tree is labeled, positioned, dimensioned and identified. The limit of this study only measures the woody plants with the diameter $\left(D_{1,3}\right)>10 \mathrm{~cm}$, carried out in 10 sub-plots (10 ha) with each sub-plot having an area of 1 ha (see Figs. 1 and 2).

\subsection{Data Collection}

The field trip was carried out in 2012 and 2017. Data in 2012 were inherited from the study of Southern Institute of Ecology [8]. The data in 2017 are made by the research team from March-May 2017.

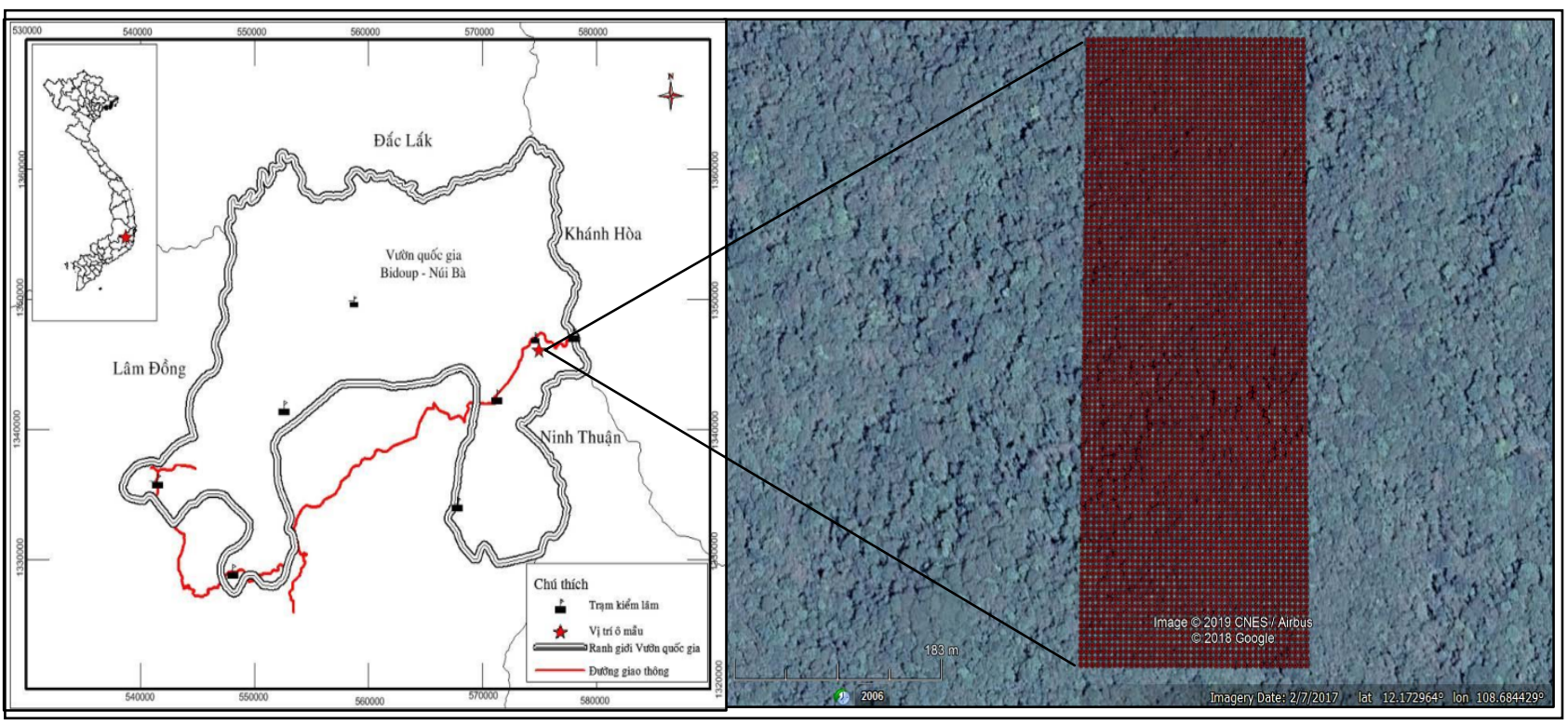

Fig. 1 Study site 10 ha at the permanent plot. 


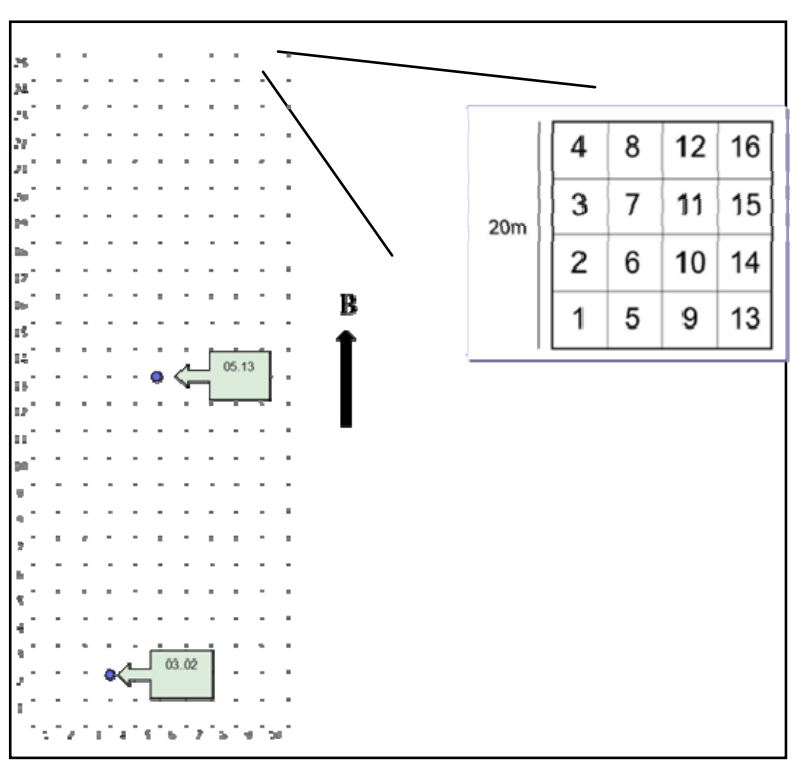

Fig. 2 Design the permanent plots.

DBH (Diameter at Breast Height) and $H$ (Tree Height) were measured according to FIPI [9], in which all woody trees were measured with DBH $>10$ $\mathrm{cm}$, and about 40 sample trees were measured in each sub-plot of 1 ha to establish an allometric equation between DBH and $\mathrm{H}$.

\subsection{Data Analysis}

Collected data were analyzed by using Excel software and Statgraphics Centuriron XV [10] to determine the allometric equation between the tree height $(\mathrm{H})$ and diameter (DBH), thereby to calculate the tree height of the entire study site, the basal area $\left(G: \mathrm{m}^{2}\right)$ and the stem volume $\left(V: \mathrm{m}^{3}\right)[9]$.

GIS softwares, such as Global Mapper v19.0, Google Earth Pro. were used to manage forest data at the permanent plot in Bidoup-Nui Ba National Park.

The study process is shown in Fig. 3.

\section{Results and Discussions}

\subsection{Allometric Equation between $\mathrm{DBH}$ and $\mathrm{H}$}

The tree height of individuals $(H)$ is one of the important indicators to calculate the volume of trees as

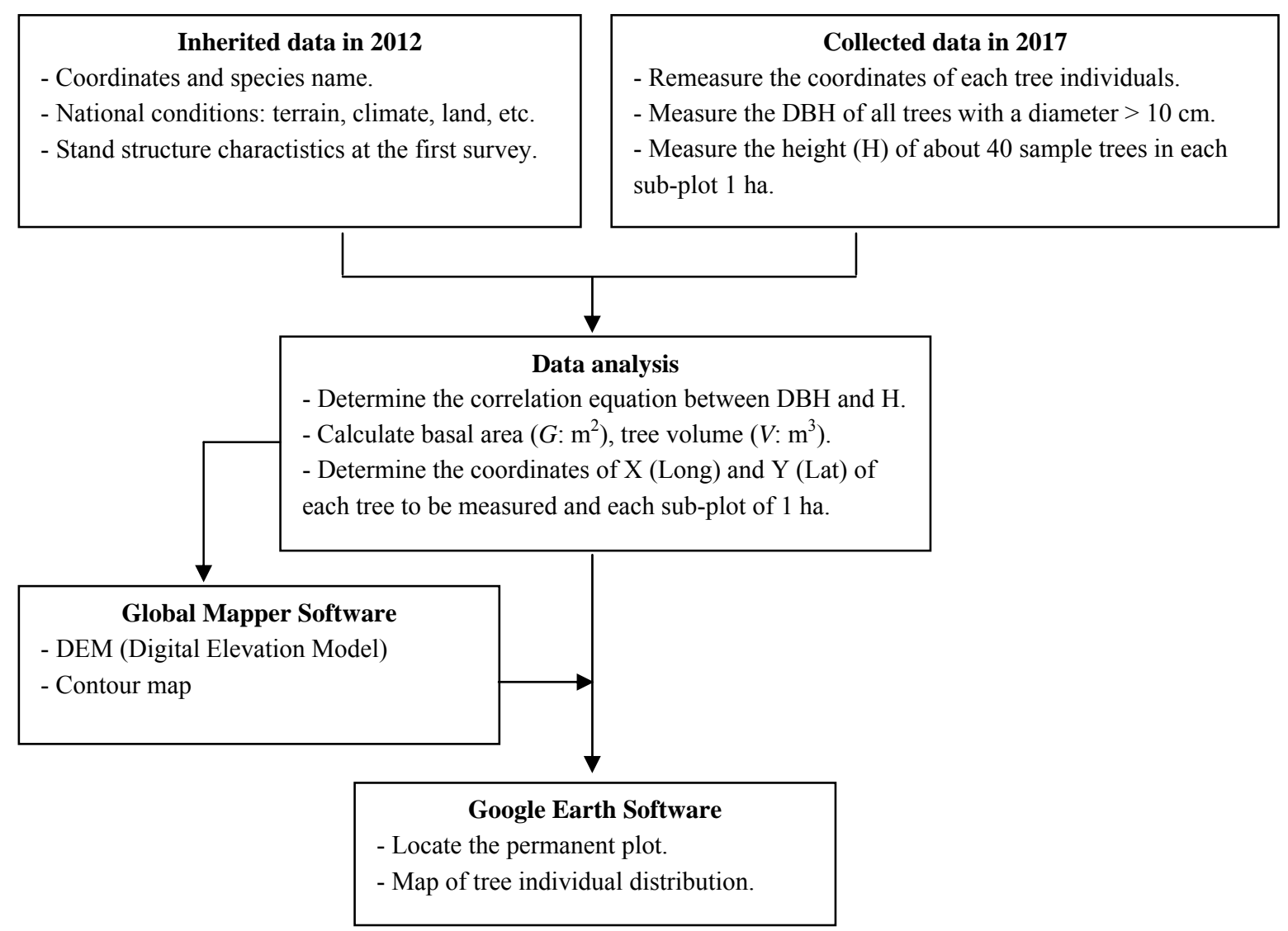

Fig. 3 The process of study. 
Table 1 Allometric equations between DBH and $H$ of ten subplots of 1 ha area $\left(8.9 \mathrm{~cm}<D_{1,3}<140.7 \mathrm{~cm}\right)$.

\begin{tabular}{llllll}
\hline \multirow{2}{*}{ Subplots } & Allometric equations & \multicolumn{3}{c}{ Statistical coefficient } \\
\cline { 3 - 6 } & $\mathrm{R}^{2}$ & SEE & SSR & MAE \\
\hline S1 & $\mathrm{H}_{1}=1 /(0.0321601+0.712002 / \mathrm{DBH})$ & $83.22 \%$ & 0.008 & 0.003 & 0.006 \\
S2 & $\mathrm{H}_{2}=\exp (3.61461-15.279 / \mathrm{DBH})$ & $80.58 \%$ & 0.17 & 1.13 & 0.14 \\
S3 & $\mathrm{H}_{3}=\exp (1.24739+0.561466 * \ln (\mathrm{DBH}))$ & $75.37 \%$ & 0.19 & 1.44 & 0.15 \\
S4 & $\mathrm{H}_{4}=\exp (1.85681+.0535684 * \mathrm{DBH})$ & $80.67 \%$ & 0.120 & 0.570 & 0.08 \\
S5 & $\mathrm{H}_{5}=1 /(0.040294+0.292272 / \mathrm{DBH})$ & $90.80 \%$ & 0.002 & 0.0002 & 0.002 \\
S6 & $\mathrm{H}_{6}=\exp (1.15259+0.529132 * \ln (\mathrm{DBH}))$ & $78.50 \%$ & 0.140 & 0.880 & 0.10 \\
S7 & $\mathrm{H}_{7}=\exp (3.58204-15.5687 / \mathrm{DBH})$ & $78.73 \%$ & 0.190 & 1.360 & 0.15 \\
S8 & $\mathrm{H}_{8}=1 /(0.0147037+0.780262 / \mathrm{DBH})$ & $79.80 \%$ & 0.007 & 0.002 & 0.006 \\
S9 & $\mathrm{H}_{9}=1 /(0.036996+0.539281 / \mathrm{DBH})$ & $98.00 \%$ & 0.002 & 0.0001 & 0.001 \\
S10 & $\mathrm{H}_{10}=1 /(0.025532+0.782251 / \mathrm{DBH})$ & $90.30 \%$ & 0.005 & 0.0009 & 0.004 \\
\hline
\end{tabular}

well as the tree volume. We can identify the tree height by many different methods such as direct measurement with height measuring instruments but the difference will be relatively large and time consuming; or based on the available height table from previous research, but the area must be relatively similar in terms of climate, soil, terrain, etc. with the previous study area; or create the allometric equation between $H$ and a more easily identifiable factor. During the growth of the trees, the tree height and $\mathrm{DBH}$ have a direct ratio and close relationship, so we determine the tree height through DBH. Here, finding out the relationship between tree height and $\mathrm{DBH}$ is significant in determining the relative tree height quickly and inexpensively. That relationship is expressed through the allometric equations made from the data of the sample trees as shown in Table 1. After analyzing the allometric equations, the selected equation is most suitable for the relationship between $\mathrm{H}$ and $\mathrm{DBH}$ with a high correlation coefficient $\left(\mathrm{R}^{2}\right)$ (not necessarily the

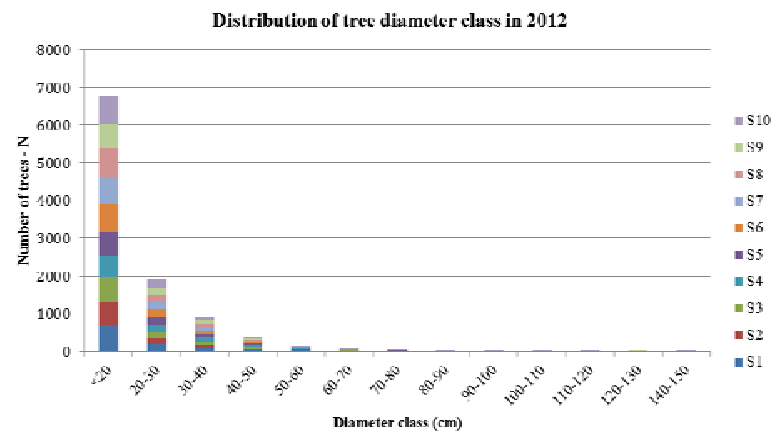

Fig. 4 Distribution of tree diameter class in 2012 and 2017. highest) but SEE (Standard Error of Estimate), SSR (Sum of Squared Residuals) and MAE (Mean Absolute Error) has the smallest value.

\subsection{Forest Structure}

\subsubsection{Distribution of Tree Diameter Class}

Diameter frequency distributions provide a useful substitute for development trends of the stands [11] and help to evaluate potential forest sustainability [12].

According to Fig. 4, the graph of distribution of trees by diameter class (N-DBH) in 2012 and 2015 is an inversed J-shape, so the observed data are inclined to be less than the average value. The number of trees is the highest at the diameter class of $10-20 \mathrm{~cm}(<20$ $\mathrm{cm}$ ), accounting for about $60 \%$ of the total number of trees of each 1-ha sub-plot and the study site $(6,780$ trees measured in 2012 and 6,593 trees measured in 2017), the diameter class which has the lowest number of trees was $>90 \mathrm{~cm}$ in diameter. The larger the diameter is, the smaller the number of trees is. This

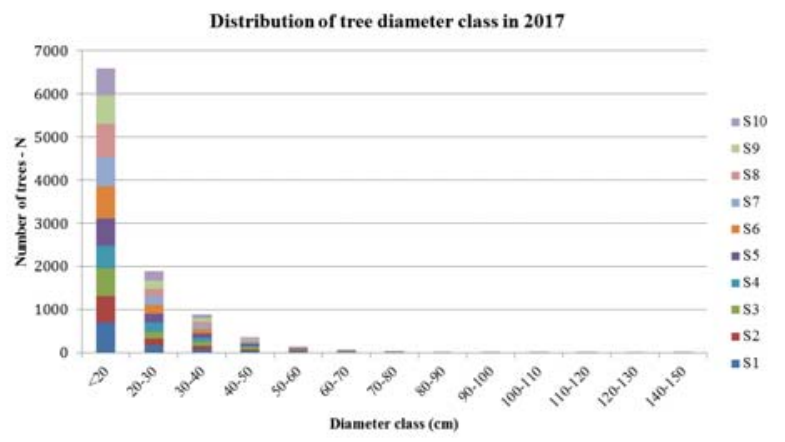




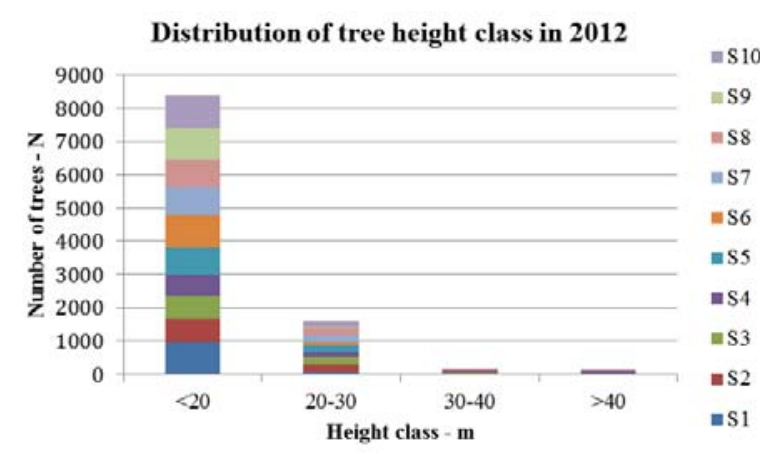

Fig. 5 Distribution of tree height class in 2012 and 2017.

indicates that the density of smaller trees in a stand is sufficient to replace the current population of larger tree. According to Aye, et al. [13], tree density is generally higher in small DBH classes compared to large DBH classes, this is a secondary forest characteristic.

\subsubsection{Distribution of Tree Height Class}

The woody tree height is also an important indicators in forest classification. Primary tropical rainforest is vertically divided into at least five layers: the overstory, the canopy, the understory, the shrub layer and the forest floor. As for woody tree stratification, there are 03 layers, including the overstory (A1: 30-40 m), the canopy (A2: 20-30 m) and the understory (A3: 8-20 m) [14].

According to Fig. 5, the graph of distribution of trees by the height $(\mathrm{N}-\mathrm{H})$ is an inversed J-shape and the number of trees tends to decrease when the height class increased. In both surveys, the highest number of trees is at the height of $<20 \mathrm{~m}$, respectively 8,402 out of 10,261 in 2012 and 8,189 out of 10,013 in 2017 were measured. In addition, the number of trees under $20 \mathrm{~cm}$ at the second measurement is lower than the first, thus ensuring the lower trees in a stand are sufficient to replace the

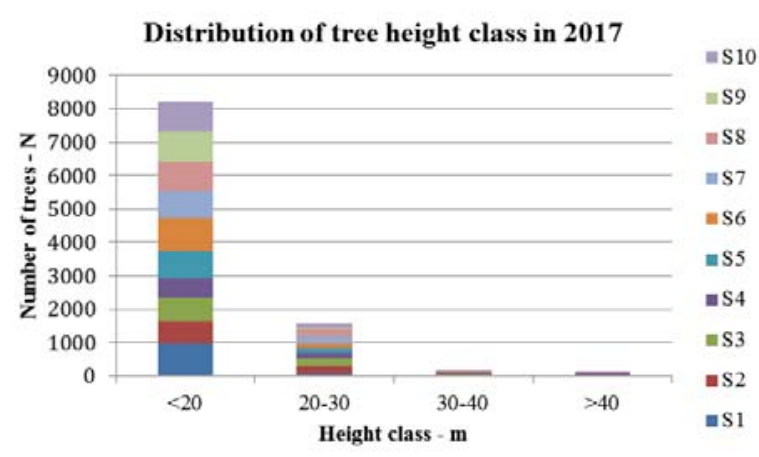

current population of higher tree.

\subsection{Using Google Earth for Forest Management}

\subsubsection{Create Study Area Boundaries}

Firstly, determine 4 points of the rectangular plot on GE (Google Earth) based on coordinates Long (X) and Lat $(\mathrm{Y})$ as Table 2 using the Add Placemark $\left(\overline{\mathcal{L}^{+}}\right)$ tool.

Then, use the Polygon $\left(\square^{+} \mid\right)$tool to set the boundary of the study area from 4 identified points (see Fig. 6).

\subsubsection{Create DEM and Contour Line Maps}

A DEM (Digital Elevation Model) is a digital model or three dimensional (3D) representation of a terrain's surface created from elevation data. DEMs can be derived through a variety of techniques, such as digitizing contours from existing topographic maps, topographic levelling, EDM (Electronic Distance Measurement), differential GPS measurements, (digital) photogrammetry, Radar remote sensing (InSAR) and Light Detection and Ranging (LiDAR). Many derivate maps can be produced from DEMs using fairly simple GIS operations. These days a wide range of data sources can be selected for the generation of DEMs. The selection depends on the data availability for a

Table 2 Coordinates of Long (X) and Lat (Y) of 4 points of the rectangular plot.

\begin{tabular}{lll}
\hline Points & Long $(\mathrm{X})$ & Lat $(\mathrm{Y})$ \\
\hline D1 & $108.686175^{\circ}$ & $12.172295^{\circ}$ \\
D2 & $108.686175^{\circ}$ & $12.176795^{\circ}$ \\
D3 & $108.688012^{\circ}$ & $12.176792^{\circ}$ \\
D4 & $108.688012^{\circ}$ & $12.172292^{\circ}$ \\
\hline
\end{tabular}


Plot in Bidoup-Nui Ba National Park
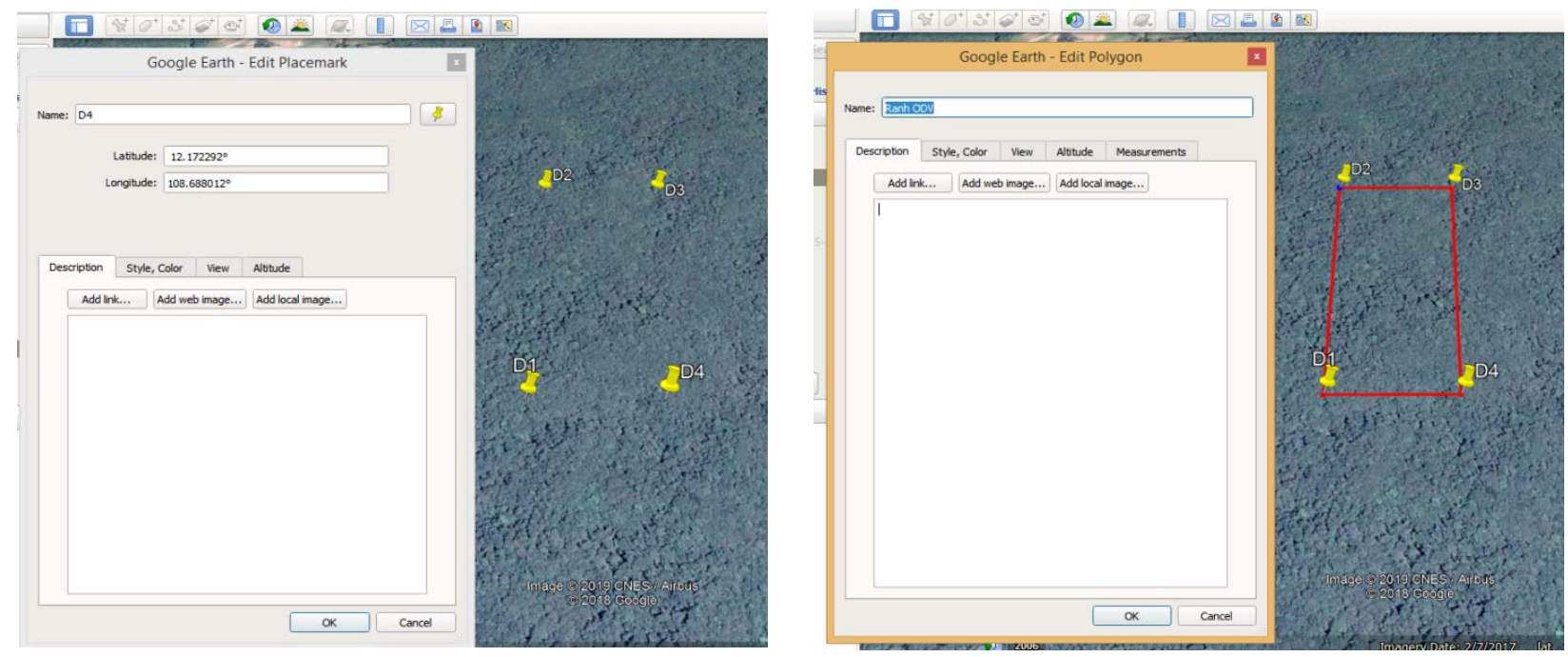

Fig. 6 Create study area points and boundaries.
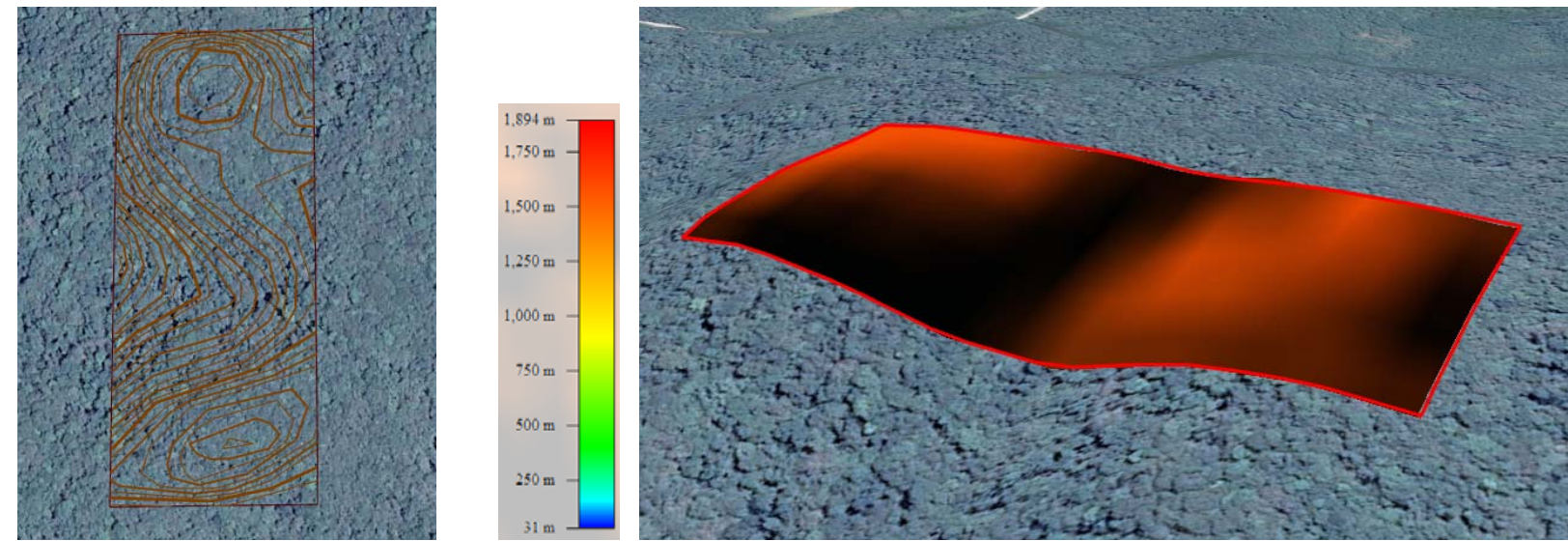

Fig. 7 Create DEM and Contour maps.

specific area, the price and the application $[15,16]$. Derivatives from DEMs can be used in heuristic analysis at small scales (e.g. hill-shading images for display as backdrop image, physiographic classification, internal relief, drainage density), in statistical analysis at regional scales (e.g. altitude zones, slope gradient, slope direction, contributing area, plan curvature, profile curvature, slope length), in physically-based modelling at local scales (local drain direction, flow path, slope gradient) and in spread modelling (detailed slope morphology, flow path) [17].

Global Mapper software helps create DEM and contour line maps from the boundaries of study area created on Google Earth to derive the characteristics of the terrain which can be applied to study the correlation relationship between the above topographic factors with species distribution, forest volume and carbon stocks in the study area (Fig. 7).

\subsubsection{Forest Management}

Characteristics and location of tree individuals measured in 2012 and 2017 are managed on Google Earth Pro. software in the following steps:

Step 1: Enter all measurement data into Excel (*: $\mathrm{xls})$, calculate the diameter (DBH: $\mathrm{cm})$, tree height $(H$ : $\mathrm{m})$, basal area $\left(G: \mathrm{m}^{2}\right)$, tree volume $\left(V: \mathrm{m}^{3}\right)$, latitude $(\mathrm{Y})$ and longitude $(\mathrm{X})$ coordinates (see Fig. 8);

Step 2: Save Excel file * xls to $* \mathrm{kml}$ or $* \operatorname{csv}$ to open on Google Earth Pro. (Fig. 9);

Step 3:

-Open Google Earth Pro. software: File $\rightarrow$ Open $\rightarrow$ Saved Folder $\rightarrow$ the converted file O1-GE.csv (Fig. 10); 


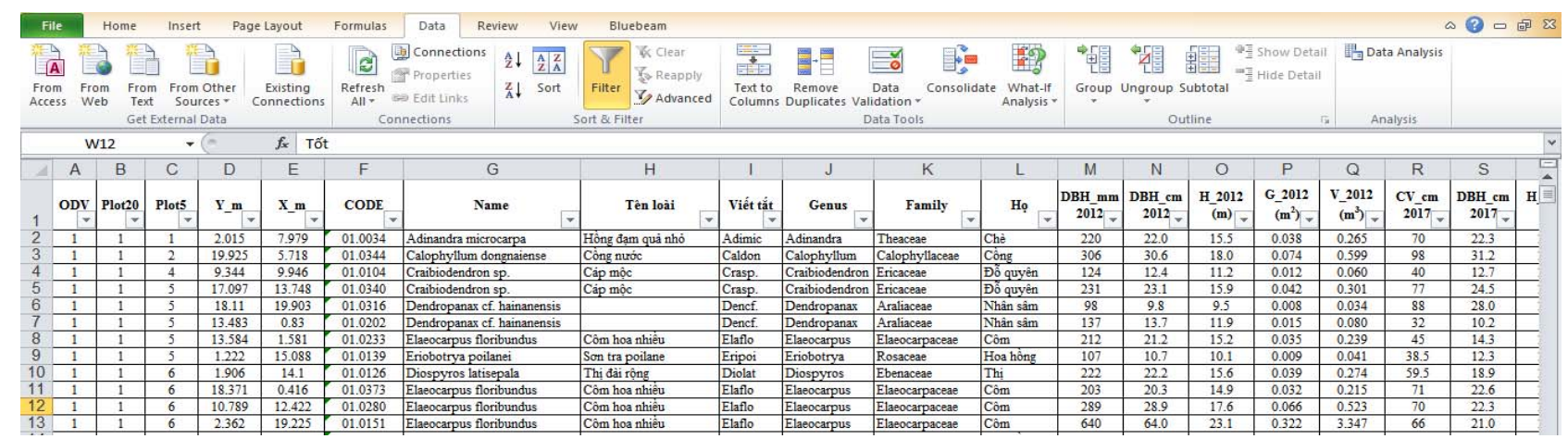

Fig. 8 Input data on Excel file.

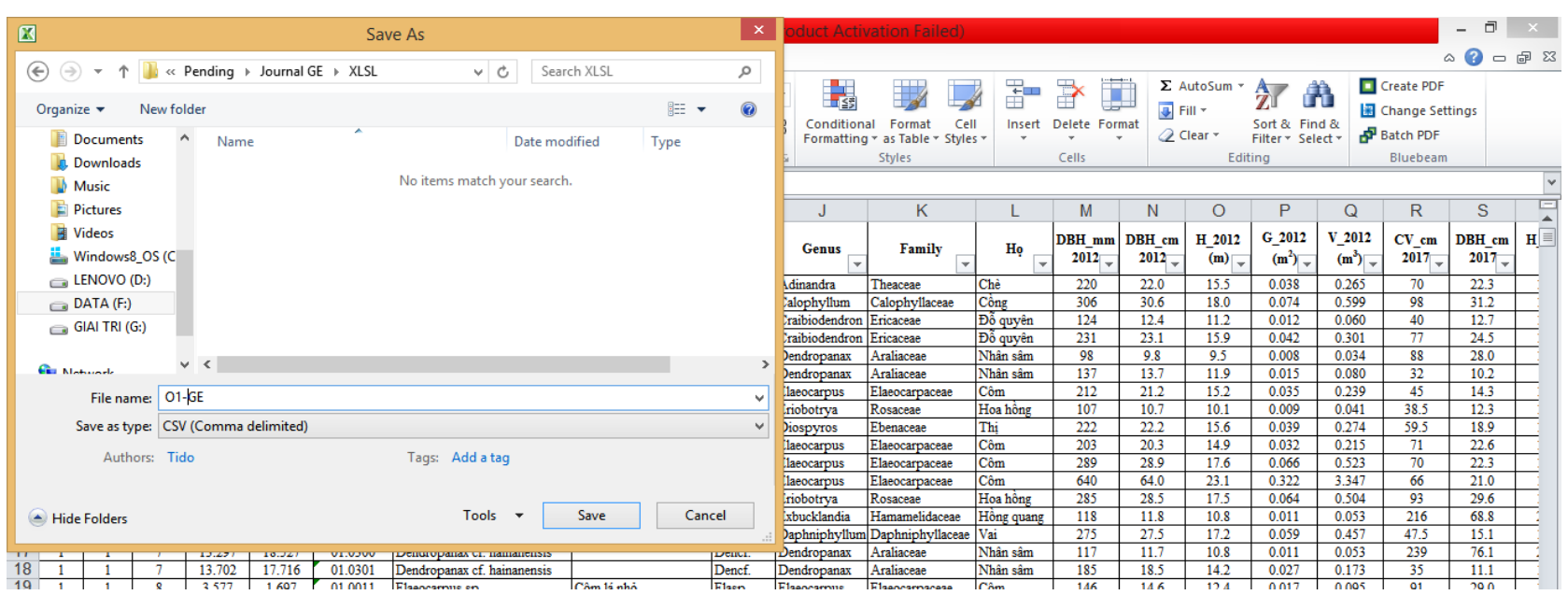

Fig. 9 Save file * $\mathbf{k m l}$ or $* \mathbf{c s v}$.

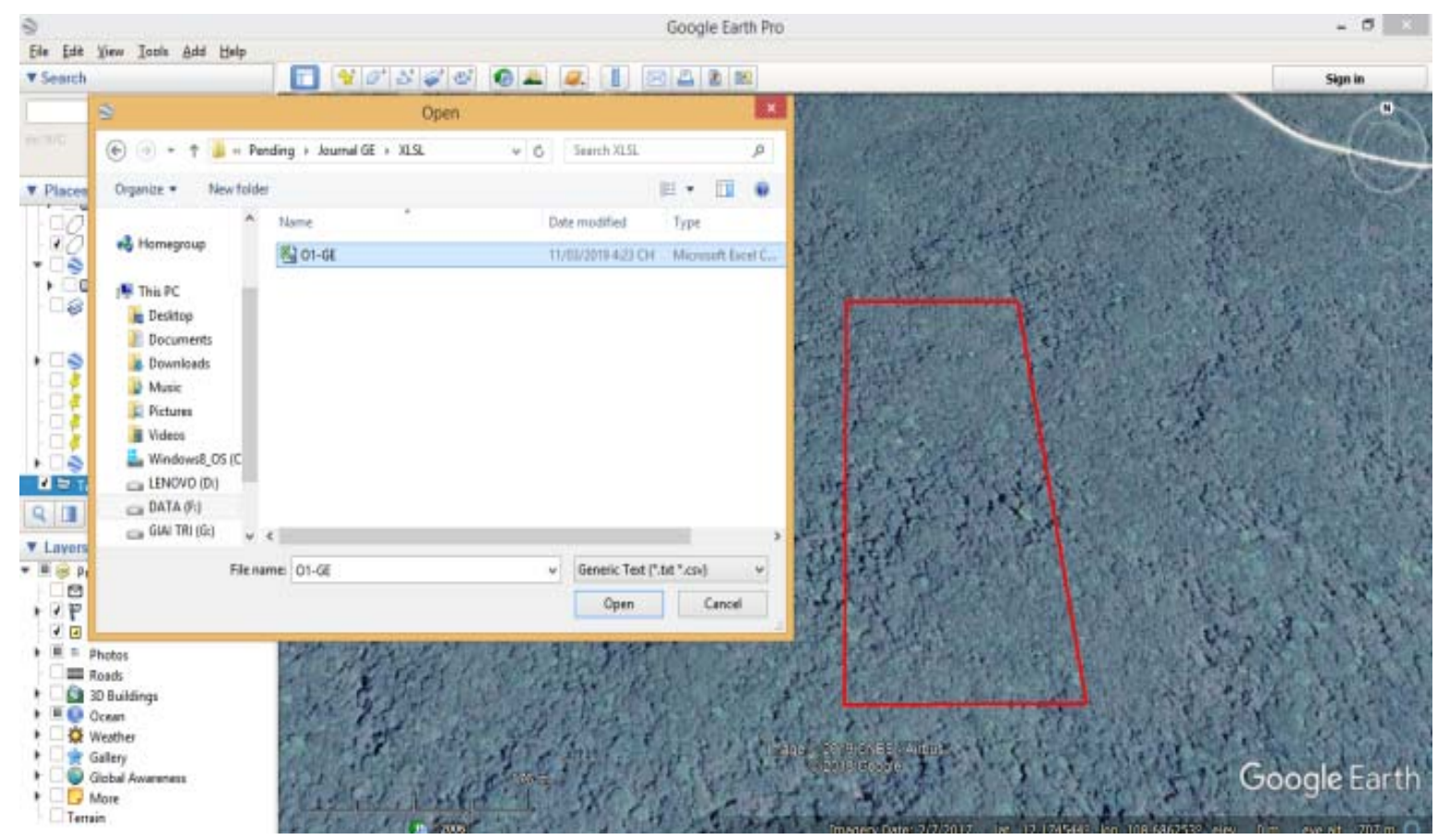

Fig. 10 Open Google Earth Pro. software. 
Forest Structure and a Sustainable Management Solution at the Permanent Plot in Bidoup-Nui Ba National Park
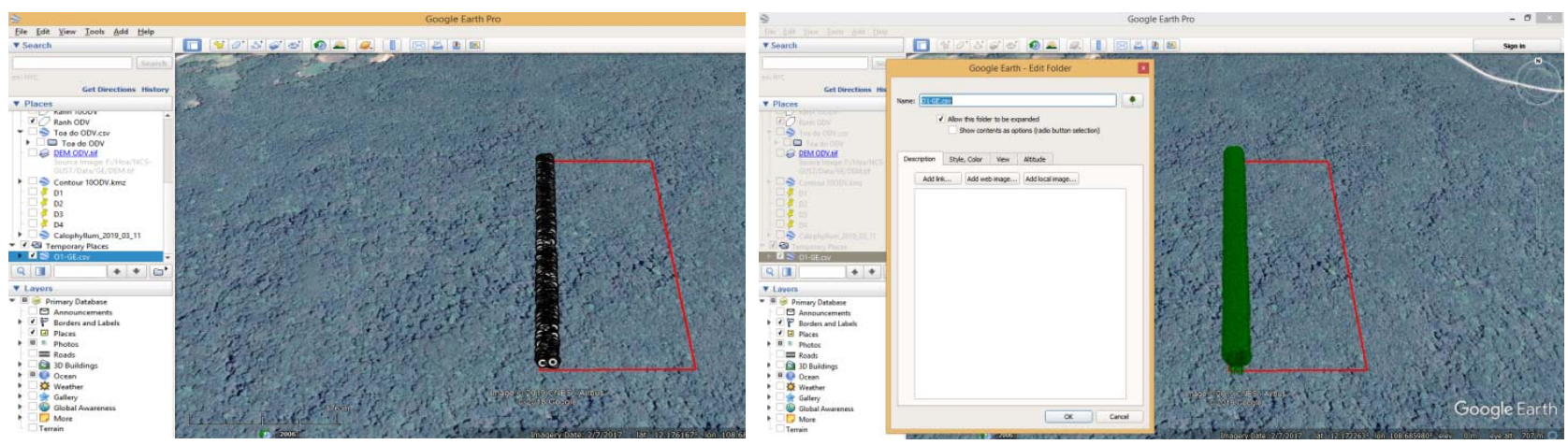

Fig. 11 Change icons in properties.

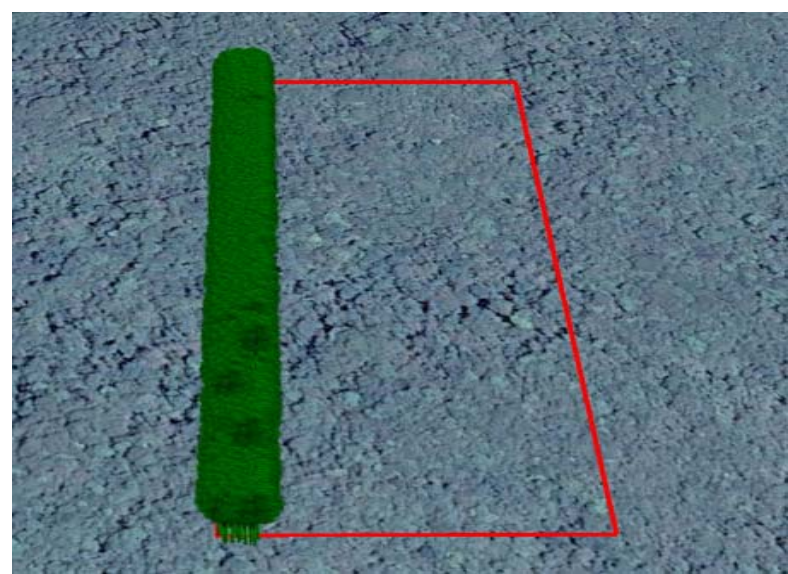

(a) Tree distribution at the 1 ha subplots (S1)

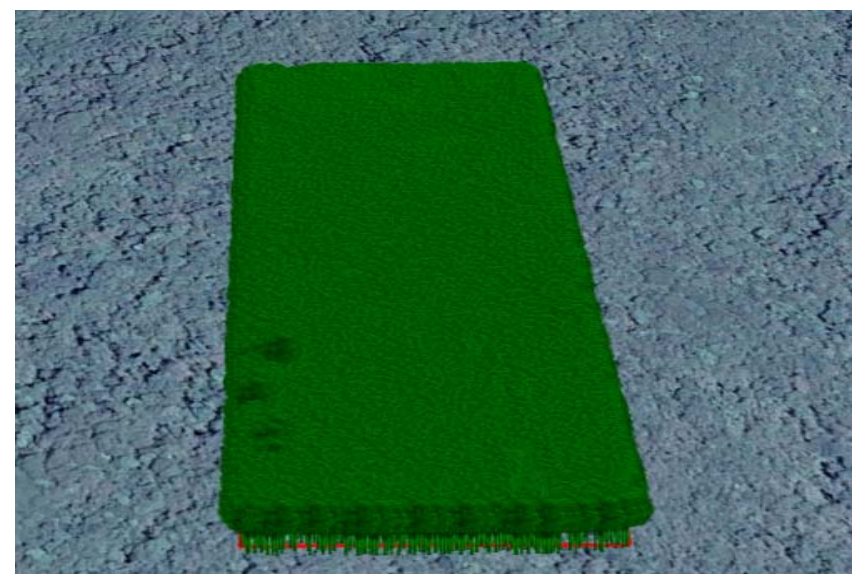

(b) Tree distribution at the study site

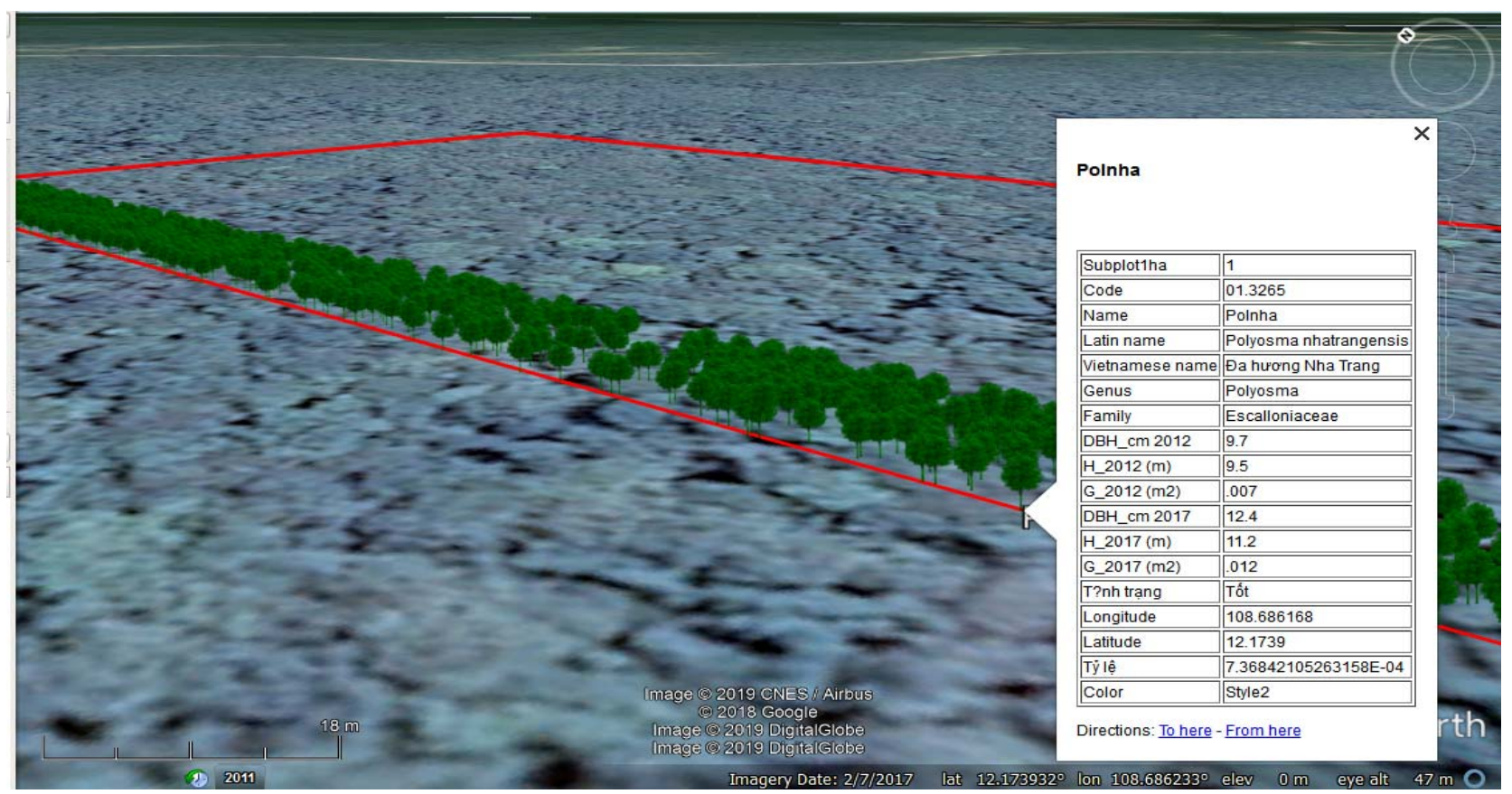

(c) Characteristics of tree individuals

Fig. 12 Forest management on GE. 
Table 3 Information of tree individuals on GE.

\begin{tabular}{ll}
\hline Contents & Example \\
\hline Subplot 1 ha & S1 \\
Code & 01.3265 \\
Name & Polnha \\
Latin name & Polyosma nhatrangensis \\
Vietnamese name & Đa hương Nha Trang \\
Genus & Polyosma \\
Family & Escalloniaceae \\
DBH_cm 2012 & 9.7 \\
H_m 2012 & 9.5 \\
G_m 2012 & 0.007 \\
DBH_cm 2017 & 12.4 \\
H_m 2017 & 11.2 \\
G_m ${ }^{2} 2017$ & 0.012 \\
Tinh trang (Status) & Good \\
Longitude (X) & $108.686168^{\circ}$ \\
Latitute (Y) & $12.1739^{\circ}$ \\
\hline
\end{tabular}

- Change the icon of individual trees icon into tree images in Properties (Fig. 11);

Step 4: All data information was shown on GE for forest management (Fig. 12).

Information of tree individuals on GE is shown in Table 3.

Thus, the whole characteristics of the measured individual trees are fully represented on Google Earth for the management and inventory of natural resources and biodiversity scientifically, easily updated, accurately and effectively.

\section{Conclusion}

In current years, facing climate changes, environment pollutions, habitat loss and biodiveristy decline, the development of GIS technology has been the optimal solution for researchers, policy makers and government to find the causes of natural resources loss and establish solutions in adaption and mitigation of harmful environement changes. The results of this paper show that Google Earth software is one of the most effective GIS tools in planning biodiversity conservation strategies and natural resource management. In addition, further studies will be conducted to assess forest dynamics in relation to other factors of the ecosystem, find the cause and predict the future changes, thereby have plans and strategies in protection of natural resources and environment in general and forest in particular.

\section{Acknowledgements}

The author would like to thank the technical support of the research team of the Southern Institute of Ecology and the students of Nong Lam University in Ho Chi Minh City who assisted in investigating research data.

\section{References}

[1] FAO. 2015. Global Forest Resources Assessment 2015-Desk Reference. Rome, Italy: Food and Agriculture Organization of the United Nations.

[2] MARD. 2006. Vietnam Forestry Development Strategy in the Period of 2006-2020. Ha Noi: Ministry of Agriculture and Rural Development, p. 115.

[3] CIFOR. 2009. Simply REDD: CIFOR's Guide to Forests, Climate Change and REDD. Bogor, Indonesia: Center for International Forestry Research, p. 11.

[4] FIPI. 2013. Project on Establishing Permanent Plots for Ecological Researches. Ha Noi: Forest Inventory and Planning Institute, p. 1.

[5] Clarke, K. C. 1986. "Advances in Geographic Information Systems." Computers, Environment, Urban Systems 10 (3-4): 175-84.

[6] Loi, N. K., et al. 2017. "Sustainable Land Use and Watershed Management in Response to Climate Change Impacts: Case Study in Srepok Watershed, Central Highland of Vietnam.” In Environmental Sustainability and Climate Change Adaptation Strategies, IGI Global, pp. 255-95.

[7] Zhang, Y., and Stovall, J. P. 2014. "Using Google Earth for Forest Management." Faculty Publications, p. 21.

[8] Truong, L. H. 2011-2015. "Establishing a Forest Dynamics Plot in Bidoup-Nui Ba National Park as Foundation for Studies in Forest Succession.” State's key science-technology program "Science and Technology for Serving Tay Nguyen Region's Social-Economic Development" KHCN-TN3/11-15 Project (Tay Nguyen 3), Southern Institute of Ecology.

[9] FIPI. 1995. Handbook of Forest Inventory and Planning. Forest Inventory and Planning Institute: Agricultural Publishing House, Ha Noi.

[10] Polhemus, N. 1980. STATGRAPHICS: Statistical Software Program. USA: Technologies, Inc.. 

Plot in Bidoup-Nui Ba National Park

[11] Lamprecht, H. 1989. Silviculture in the Tropics: Tropical Forest Ecosystems and Their Tree Species: Possibilities and Methods for Their Long-Term Utilization (no. 634.95 L239s ing.). Eschborn, DE: GTZ.

[12] Rubin, B. D., Manion, P. D., and Faber-Langendoen, D. 2006. "Diameter Distributions and Structural Sustainability in Forests." Forest Ecology Management 222 (1-3): 427-38.

[13] Aye, Y. Y., Pampasit, S., Umponstira, C., Thanacharoenchanaphas, K., and Sasaki, N. 2014. "Floristic Composition, Diversity and Stand Structure of Tropical Forests in Popa Mountain Park." Journal of Environmental Protection 5 (17): 1588-602.
[14] Trung, T. 1978. The Vegetation Cover in Vietnam. Hanoi: Science and Technology Publishing House.

[15] CHARIM. 2014. "Digital Elevation Models." In Data Management. University of Twente, Holland: Caribbean Handbook on Risk Information Management.

[16] Van Westen, C. J. 2013. "Remote Sensing and GIS for Natural Hazards Assessment and Disaster Risk Management." Treatise on Geomorphology 3: 259-98.

[17] Moore, I. D., Grayson, R., and Ladson, A. 1991. "Digital Terrain Modelling: A Review of Hydrological, Geomorphological, and Biological Applications." Hydrological Processes 5 (1): 3-30. 